\title{
AN INSIGHT INTO THE VOLUME COMPONENT GENERATED FROM RISAT-1 HYBRID POLARIMETRIC SAR DATA FOR CROP BIOPHYSICAL PARAMETERS RETRIEVAL
}

\author{
Hari Shanker Srivastava ${ }^{1, *}$, Thota Sivasankar ${ }^{1}$, Parul Patel $^{2}$ \\ ${ }^{1}$ Indian Institute of Remote Sensing (ISRO), Dehradun-248001, India - hari.isro@gmail.com, siva.iirs@gmail.com \\ ${ }^{2}$ Space Applications Centre (ISRO), Ahmedabad-380015, India - parul@ sac.isro.gov.in
}

\section{Commission V, SS: Natural Resources Management}

KEY WORDS: Hybrid polarimetry, Synthetic aperture radar, Volume component, RISAT-1

\begin{abstract}
:
Polarimetric parameters have been extensively used for target parameters retrieval than backscattering coefficients. In previous studies, volume component generated from polarimetric SAR data has been considered as the return signal component from vegetation and intern used this for biophysical parameters retrieval. Un-polarized component of the return signal has been considered as volume component. The present study is mainly focused to analyze the volume component generated from C-band RISAT-1 hybrid polarimetric SAR data from wheat crop. Three temporal datasets acquired at $\sim 31^{\circ}$ central incidence angle between Jan and Mar 2016 over parts of Bharatpur and Mathura districts located in Rajasthan and Uttar Pradesh (India) have been used in this study. Water Cloud Model with Gaps has been considered for modeling the first Stokes parameter $\left(\mathrm{g}_{0}\right)$, which represents total intensity of return signal, from wheat crop using LAI and Interaction factor as vegetation descriptors. The vegetation component derived using calibrated Water Cloud Model with Gaps has been analyzed with volume component derived from RISAT-1 hybrid polarimetric SAR data. The analyses observed that a significant difference during lower LAI values and shown comparably during higher LAI values. The higher values of volume component derived from RISAT-1 SAR data than modeled vegetation component indicates that the volume component can also be generated by underneath soil. It is also observed the difference in derived un-polarized component and modeled vegetation component has shown higher correlation with underneath soil moisture than directly correlating with derived un-polarized component. This study indicates that the volume component derived from hybrid polarimetric SAR data has return signals from vegetation as well as underneath soil.
\end{abstract}

\section{INTRODUCTION}

Crop biophysical parameters such are leaf area index (LAI), biomass, plant water content (PWC) and plant height, dynamics over a period during crop growing season is a vital input parameter for several yield estimation models (Bassoet al., 2013; Doraiswamy et al., 2003). Since these parameters are highly variable spatially as well as temporally, conventional insitu measurements become laborious and time consuming. In contrast to ground based instrument measurements, remote sensing data has gained considerable importance for agricultural applications by providing various spatial and temporal resolution images at scales ranging from local to global. The advancement of Synthtetic Aperture Radar (SAR) can provide un-interrupted high resolution earth observation data even during cloudy, smoke and smog situations due to the sensor operation at microwave frequencies (Sivasankar et al., 2018). Radar remote sensing data can provide better crop cover information by interacting with entire plant volume than optical remote sensing. The return signal from agricultural fields is a complex function of sensor parameters such as frequency, incidence angle and polarization along with crop cover characteristics and underneath soil characteristics (Srivastava et al., 2009; Srivastava, 2007; Sivasankar et al., 2018). Therefore, retrieving a specific crop biophysical parameter from the radar return signal has become a challenging task still yet."

The sensitivity of backscattering coefficients $\left(\sigma^{\circ}\right)$ generated from SAR data towards crop biophysical parameters have been

\footnotetext{
* Corresponding author
}

extensively analyzed in previous studies. It is observed that the P- \& L-band is useful for broad leaf crops and C- \& X-bands for narrow leaf crops (Macelloni et al., 2001; Fontanelli et al., 2013; Paloscia, 1998). Patel et al., 2006 identified that the cross polarized SAR backscatter is more sensitive towards plant density than co-polarization. Decomposition parameters i.e., volume component, even bounce and odd bounce derived from polarimetric SAR data provides better target information than backscattering coefficients. In particularly, volume component, which is proportional to un-polarized component of the return signal, is identified as highly sensitive towards vegetation biophysical parameters due to the dielectric discontinuity. Poolla (2013) had used L-band full polarimetric ALOS PALSAR data to retrieve forest biomass volume over Dudhwa national park, India. The volume component generated using Yamaguchi et al. (2006) has considered as backscatter signal component from vegetation in Water Cloud Model based semiempirical model. Banerjee (2012) had estimated tea bush biomass using L-band full polarimetric ALOS PALSAR data over Sarusarai tea estate, Assam, India. Volume component generated using Freeman II decomposition technique has been used in Water Cloud Model based semi-empirical model. Although previous studies have observed significant improvements in the biophysical parameters estimation accuracy by using volume component over backscattering coefficients, but it was not analyzed the actual component of the return signal from vegetation in volume component derived from decomposition technique.

Although previous studies have observed significant 
improvements in the biophysical parameters estimation accuracy by using volume component over backscattering coefficients, but it was not analyzed the actual component of the return signal from vegetation in volume component derived from decomposition technique. In this study, Water Cloud Model with Gaps has been considered for modeling the first Stokes parameter $\left(\mathrm{g}_{0}\right)$, which represents total intensity of return signal, from wheat crop. Furthermore, the un-polarized component derived from RISAT-1 hybrid polarimetric SAR data has been analyzed with the backscatter component from vegetation as measured from calibrated Water Cloud Model with gaps using in-situ crop biophysical parameters and underneath soil moisture.

\section{MATERIALS AND METHODS}

\subsection{Study area and datasets}

Since high incidence angle SAR data is more sensitive to the agricultural crop characteristics, three RISAT-1 hybrid polarimetric SAR datasets were acquired at $\sim 31^{\circ}$ incidence angle over parts of Bharatpur and Mathura districts located in Rajasthan and Uttar Pradesh states respectively in India during Jan - Mar 2016. The study area is usually dominated with wheat and mustard crops during rabi season. The Yamuna canal passing through the Mathura district enables the irrigation water for crops in this area. The location of study area is given in the Fig 1.The procured RISAT-1 hybrid polarimetric SAR data details along with their orbital parameters, are shown in Table 1.Since the sensor parameters are same during the both campaigns, the changes in the sensitivity of parameters generated from RISAT-1 hybrid polarimetric SAR data towards LAI of paddy crop were considered it as caused by the crop growth.

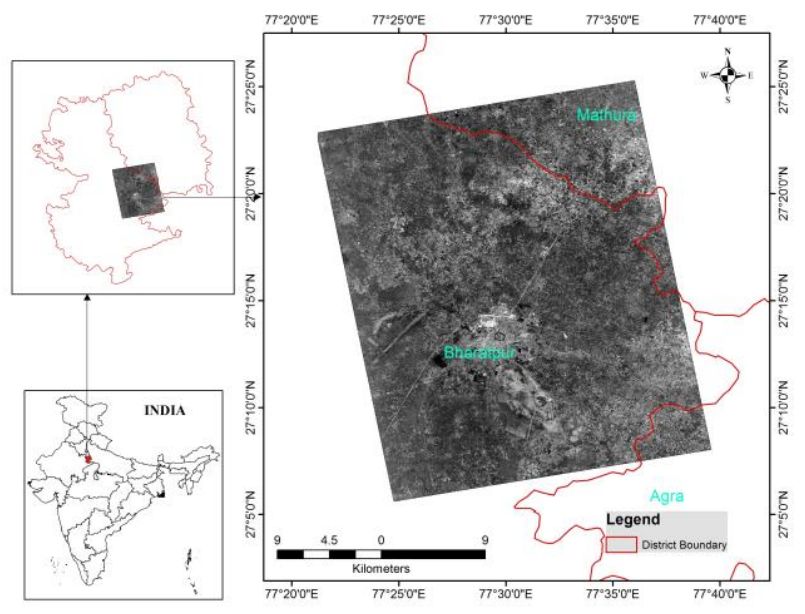

Figure 1. The location of study area

Table 1. Specifications of SAR data and sensor parameters used in this study

\begin{tabular}{|c|c|c|c|}
\hline DATE OF PASS & $\begin{array}{c}\text { 25 January } \\
2016\end{array}$ & $\begin{array}{c}\text { 19 Febrauary } \\
2016\end{array}$ & $\begin{array}{c}15 \text { March } \\
2016\end{array}$ \\
\hline SATELLITE & RISAT-1 & RISAT-1 & RISAT-1 \\
\hline PLATFORM & Space & Space borne & Space borne \\
\hline
\end{tabular}

\begin{tabular}{|c|c|c|c|}
\hline & borne & & \\
\hline MODE & FRS-1 & FRS-1 & FRS-1 \\
\hline BAND/SENSOR & C/SAR & C/SAR & C/SAR \\
\hline POLARIZATION & RH/RV & RH/RV & RH/RV \\
\hline $\begin{array}{c}\text { CENTRAL } \\
\text { INCIDENCE } \\
\text { ANGLE }\end{array}$ & $\sim 31^{\circ}$ & $\sim 31^{\circ}$ & $\sim 31^{\circ}$ \\
\hline $\begin{array}{c}\text { AZIMUTH } \\
\text { RESOLUTION }\end{array}$ & 3 & 3 & 3 \\
\hline $\begin{array}{c}\text { RANGE } \\
\text { RESOLUTION }\end{array}$ & 2 & 2 & 2 \\
\hline
\end{tabular}

\subsection{Hybrid polarimetric parameters}

The RISAT-1 hybrid polarimetric SAR datasets were radiometrically calibrated using the following equation as given by Mishra et al., (2015).

$\sigma_{(d B)}^{o}=10 \times \log _{10}\left(\frac{D N_{i}^{2}}{C_{i i}}\right)+10 \times \log _{10}\left(\frac{\sin \left(\theta_{i}\right)}{\sin \left(\theta_{\text {center }}\right)}\right)$

Where, $\mathrm{C}_{\mathrm{ii}}$ is calibration constant, $\theta_{\mathrm{i}}$ represents incidence angle of $\mathrm{i}^{\text {th }}$ pixel and $\theta_{\text {center }}$ is central incidence angle.

Stokes (1852) defined a set of four parameters based on two linear orthogonal polarization signals (horizontal and vertical) to describe the polarization state of the electromagnetic signal. These parameters were used to analyze the return signal from the agricultural target by illuminating right circular polarized signal. The Stokes parameters were generated using following equation.

$g=\left[\begin{array}{l}g_{0} \\ g_{1} \\ g_{2} \\ g_{3}\end{array}\right]=\left[\begin{array}{c}\left\langle\left|E_{R H}\right|^{2}+\left|E_{R V}\right|^{2}\right\rangle \\ \left\langle\left|E_{R H}\right|^{2}-\left|E_{R V}\right|^{2}\right\rangle \\ 2 \times \operatorname{Re}\left\langle E_{R H} E_{E V}^{*}\right\rangle \\ -2 \times \operatorname{Im}\left\langle E_{R H} E_{E V}^{*}\right\rangle\end{array}\right]$

Here, $\mathrm{E}$ is the complex backscattered electric field, $|\ldots|$ denotes absolute value, $\langle\ldots\rangle$ represents average, $*$ indicates complex conjugate and $\mathrm{Re} \& \mathrm{Im}$ denotes the real and imaginary parts of the complex respectively.

Several hybrid polarimetric decomposition techniques have been proposed by previous studies including $\mathrm{m}-\delta$ by Raney (2007); m- $\chi$ by Raney et al., (2012); m- $\alpha$ by cloude et al., (2012). Almost in all space decomposition techniques, volume component has been considered as the square root of unpolarized component in return signal. The mathematical expression for volume component is given in Equation (3).

Volume component $=\sqrt{(1-m) \times g_{0}}$

Where, ' $m$ ' represents the degree of polarization derived from Stokes parameters as follows:

$m=\frac{\sqrt{g_{1}^{2}+g_{2}^{2}+g_{3}^{2}}}{g_{0}}$

\subsection{Ground truth data collection}

The farmers' fields of minimum size, $22 \times 22 \mathrm{~m}^{2}$ were considered as suggested by Patel \& Srivastava (2013) for RISAT-1 FRS-1 mode by accounting the characteristic-fading 
phenomenon of SAR signal. Ground-truth campaigns in synchronous with RISAT-1 passes were conducted to collect information about crop and soil samples. The AccuPAR model LP-80 was used to measure in-situ LAI in sequence of two above and five below canopy samples with 5 replications at each field. Crop and soil samples were collected during campaigns and measured biomass, plant water content and volume for crop as well as soil moisture, roughness, texture and type of soil. The field photos taken during ground-truth campaigns are given in Fig. 2 to illustrate the change in crop structure due to the crop growth.

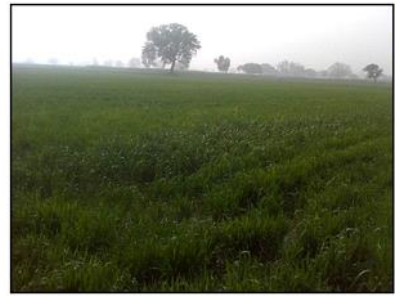

(a) $25-\operatorname{Jan}-2016$

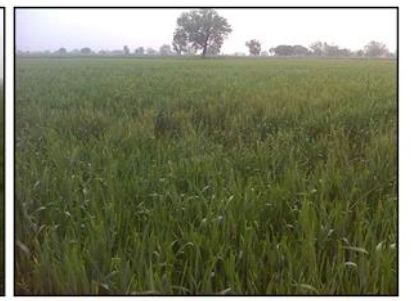

(b) $19-\mathrm{Feb}-2016$

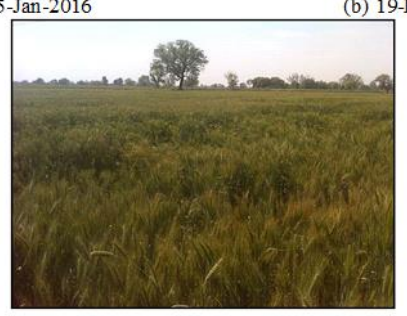

(c) 15-Mar-2016

Figure 2. Ground-based photographs of a wheat field taken on (a) 25-Jan-2016 (b) 19-Feb-2016 and (c) 15-Mar-2016

\subsection{Water Cloud Model:}

Attema and Ulaby (1978) developed the Water Cloud Model to describe the relationship between the backscatter coefficient with the vegetation biophysical and soil moisture parameters. Because of the relative dielectric constant of air and dry vegetation are 1.0 and approximately 1.5 in comparison to water with approximately 80 at microwave frequencies (Srivastava et al., 2006). In this model, it was assumed that canopy as identical water droplets with uniformly distributed according to a Poisson process over a horizontal plane surface which is represented as ground. Attema and Ulaby (1978) calibrated the model for backscattering coefficients of $\mathrm{HH}$ and VV polarizations in the $8-18 \mathrm{GHz}$ frequency range supported by ground truth data of alfalfa, corn, milo and wheat. It was observed correlation coefficients in the range of 0.7 to 0.99 depending on frequency, polarization and crop type. Although the model was initially developed in context to understand the backscatter from agricultural crops, later the same has been also used for forest applications (Fransson, 1999; Kumar, 2009; Peregon and Yamagata, 2013). The modeled total backscatter from a crop canopy at a given incidence angle is given as an incoherent sum of the contribution of backscatter from a vegetation canopy and that from soil, attenuated twice by the vegetation layer:

$\sigma_{\text {total }}^{o}=\sigma_{\text {veg }}^{o}+L^{2} \cdot \sigma_{\text {soil }}^{o}$
With, $\sigma_{\text {veg }}^{o}=A \cdot V_{1} \cdot \cos \theta\left(1-L^{2}\right)$

$L^{2}=\exp \left(-2 \cdot B \cdot V_{2} \cdot \sec \theta\right)$

$\sigma_{\text {soil }}^{o}=C+D \cdot M_{v}$

Where, V1 and V2 are the vegetation descriptors; A and B are vegetation specific coefficients while $\mathrm{C}$ and $\mathrm{D}$ are the soil specific coefficients at a given frequency, polarization and incidence angle; and $\mathrm{Mv}$ is the volumetric soil moisture.

In most studies, the vegetation descriptors V1 and V2 were considered in a combination of vegetation water content (Sikdar and Cumming, 2004; Paloscia et al., 2013), leaf area index (Champion and Guyot, 1991; Prevot et al., 1993) and NDVI (El Hajj et al., 2016). Sugandh et al., (2017) analyzed the hybrid polarized backscatter (RH and RV) based on Water Cloud Model using various combinations of vegetation descriptors as used in Ulaby et al., 1984; Prevot et al., 1993; DabrowskaZielinska et al., 2007. In addition to these parameterizations, it was also attempted with $\mathrm{V}_{1}$ and $\mathrm{V}_{2}$ as LAI and Interaction Factor (IF) respectively and observed significant improvement for both RH and RV backscatter simulation than the previous approaches. IF was first coined by Patel et al., (2006), which represents the planar distribution of water droplets within the plant volume by excluding the air gaps, as given in Equation (9) to estimate wheat yield (number of grains) using cross-polarized Enivsat-1 ASAR data.

Interaction factor $(I F)=$ (Plant moisture $\times$ Volume of plant $\times$ palnt density) Plant height

Numerous researchers have analyzed Water Cloud Model and suggested various improvements for better backscatter simulation from vegetation. One such the most popular Modified Water Cloud Model is Water Cloud Model with gaps developed by Askne et al., 1995. The model is given as:

$\sigma_{\text {total }}^{o}=(1-\eta) \sigma_{\text {soil }}^{o}+\eta\left[\sigma_{\text {soil }}^{o} \cdot L^{2}+\sigma_{\text {veg }}^{o}\left(1-L^{2}\right)\right]$

Where, $\eta$ represents area-fill factor, which is proportional to LAI.

In this modified model, three basic scattering mechanisms of microwave signal with vegetation have been considered, such are (1) direct scattering made by the ground through the gaps in the canopy; (2) direct scattering from the ground attenuated by the canopy and (3) direct scattering from the vegetation layer without attenuation. This study has considered the Water Cloud Model with gaps for calibrating the Stokes first parameter $\left(\mathrm{g}_{0}\right)$, which represents the total intensity of the return signal, by considering the vegetation descriptors $\mathrm{V}_{1}$ and $\mathrm{V}_{2}$ as LAI and IF.

\section{RESULTS AND DISCUSSION}

The relationship between ' $\mathrm{g}_{0}$ ' and soil moisture (gravimetric soil moisture) from bare fields has been analyzed using regression 
approach as given in Equation 8. The analysis observed that the soil specific coefficients as $C=0.0991$ and $D=0.0103$. The first Stokes parameter ' $\mathrm{g}_{0}$ ' has been simulated based on water cloud model with gaps as given in Equation 10 using in-situ crop biophysical parameters and underneath soil moisture. The vegetation descriptors such are $\mathrm{V}_{1}$ and $\mathrm{V}_{2}$ were considered as LAI and IF respectively. From this analysis, the vegetation coefficients A and B were identified as 318.85 and 2.3E-05 respectively. The estimated $\mathrm{g}_{0}$ using calibrated water cloud model with gaps and g0 derived from RISAT-1 SAR data have shown correlation coefficient and root mean square error (rmse) of 0.9 and 0.0378 respectively. The scatter plot of estimated $\mathrm{g}_{0}$ and observed $\mathrm{g}_{0}$ is given in Fig. 3. The calibrated model has shown good agreement of $g_{0}$ with 1-1 line in the range between 0.1 and 0.4 whereas it was underestimated for greater than 0.4 values.

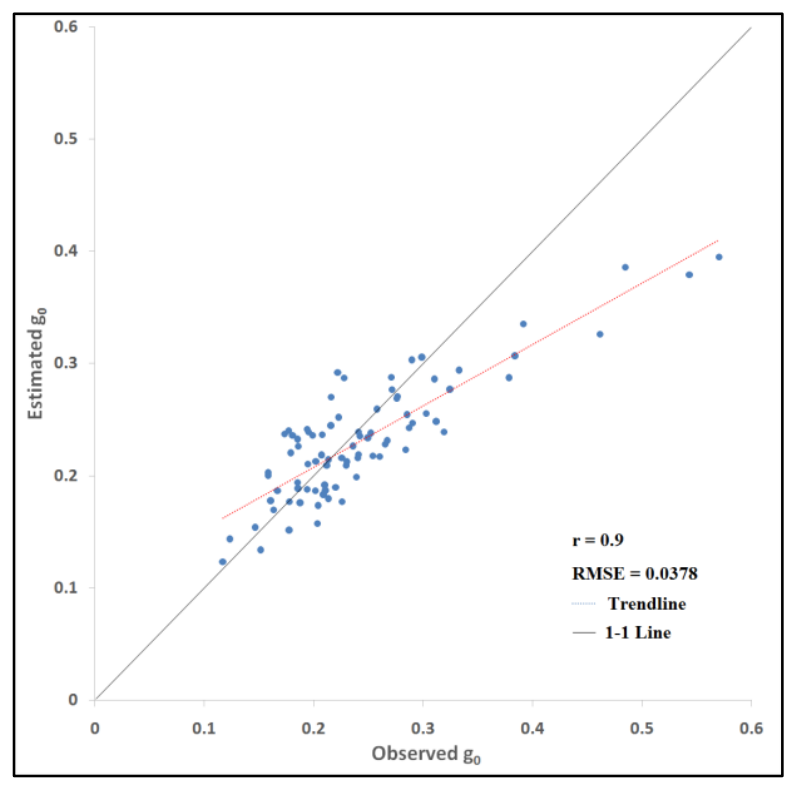

Figure 3. Scatterplot of estimated and observed $g_{0}$

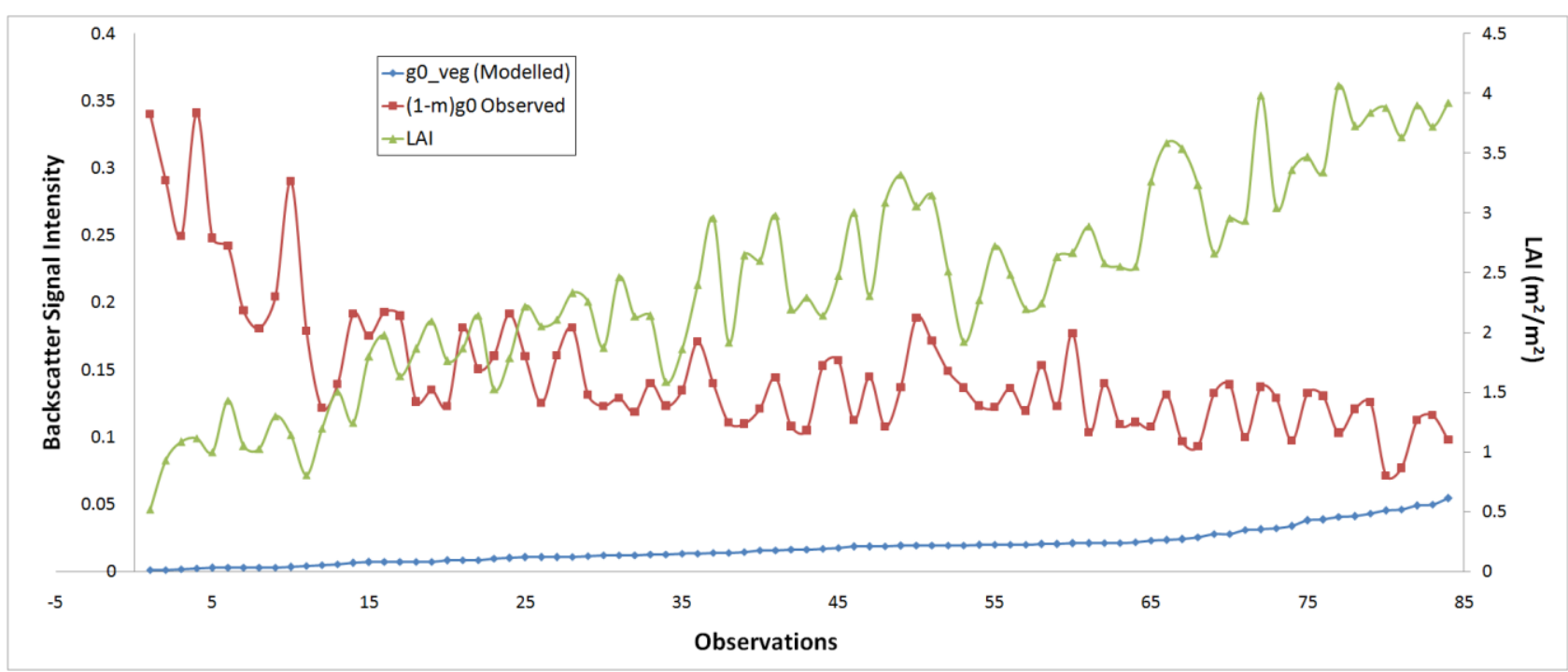

Figure 4. Plot of $\mathrm{g}_{0} \_$veg (modeled) and (1-m)g observed in corresponding with in-situ LAI

The calibrated water cloud model with gaps has been used to estimate the return signal component from vegetation (g0_veg) using in-situ crop biophysical parameters and underneath soil moisture. To understand the influence of crop biophysical parameters on the un-polarized component of return signal, the modeled return signal from vegetation and un-polarized component , (1-m) $\mathrm{g}_{0}$, as observed from RISAT-1 hybrid polarimetric SAR data has been analyzed in corresponding with in-situ LAI (given in Fig. 4). It is observed that the difference between modeled return signal from vegetation and unpolarized component observed are gradually decreased with increase in LAI. This clearly indicates that the illuminated signal interacting with underneath soil through the gaps has significant impact on un-polarized component of the return signal. Since the vegetation covers less are with lower LAI values during the stem elongation and ripening stages, the difference is higher where as the difference is significantly decreased with the increase in LAI during milking stage of crop growth. Therefore, the volume component generated from polarimetric SAR data may leads to significant errors during lesser LAI values.
The illuminated fully polarized signal becomes un-polarized when the signal passes through dielectric discontinuity medium. Since the vegetation components such are leaves, stem and seeds have different dielectric properties, as the signal passes through these vegetation components with air gaps between them leads the return signal from vegetation as un-polarized. However, the water content present in the soil also acts as the dielectric discontinuity medium with water droplets, soil particles and air gaps. Sharma et al., (2016) observed that the volume component derived from polarimetric SAR data (acquired at low incidence angle) is highly sensitive towards the underneath soil moisture over wheat crop covered agricultural fields. In particularly, the difference between modeled return signal from vegetation and un-polarized component is combined effect of underneath soil moisture and the soil exposure, (1LAI). The scatter plot of differences in observed un-polarized component and modeled vegetation return signal with product of soil exposure and underneath soil moisture as given in Fig. 5 supports the above statement. 


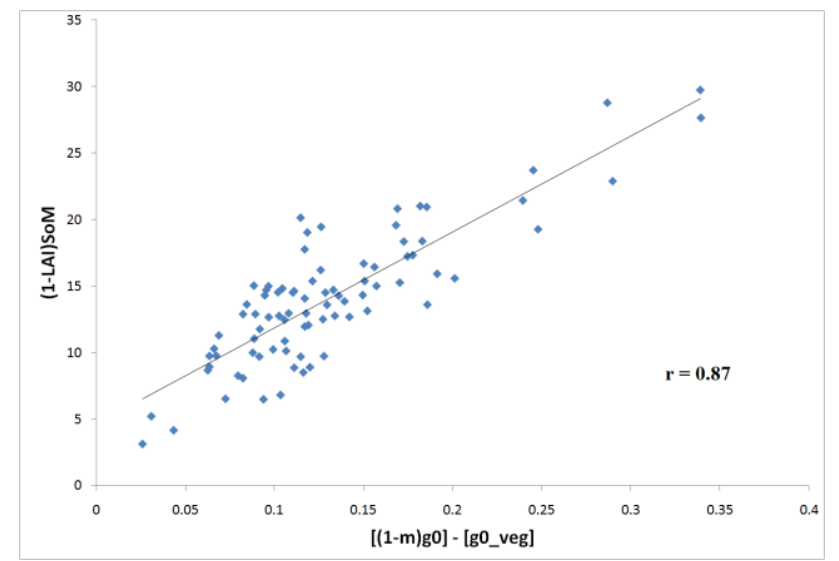

Figure 5. The scatter plot of differences in observed unpolarized component and modeled vegetation return signal with product of soil exposure and underneath soil moisture

\section{CONCLUSION}

This study has made an attempt to study the insights into the volume component generated from RISAT-1hybrid polarimetric SAR data for crop biophysical parameters. The total intensity of return signal $\left(\mathrm{g}_{0}\right)$ from wheat crop has been calibrated using water cloud model with gaps with in-situ crop biophysical parameters and underneath soil moisture. It is observed that the difference between observed un-polarized signal intensity and modeled return signal from vegetation is significant and also decreased with increase in LAI values. It is also observed that this difference is highly correlated with product of soil exposed and underneath soil moisture. This indicates that the volume component derived from hybrid polarimetric SAR data has information of crop cover as well as underneath soil moisture.

\section{REFERENCES}

Askne, J., Dammert, P. B. G., Fransson, P., Israelsson, H., and Ulander, L. M. H., 1995. Retreival of forest parameters using intensity and repeat pass interferometric SAR information. Proceedings of retrieval of Bio and Geophysical parameters from SAR data for land Application, pp.119-129.

Attema, E., and Ulaby, F., 1978. Vegetation modeled as a water cloud. Radio Science, 13 (2), pp. 357-364.

Banerjee, A., 2012. Assessment through polarimetric decomposition and semi-empirical modeling. M.Sc. Thesis, Faculty of Geo-information Science and Earth Observation, University of Twente.

Basso, B., Cammarano, D., and Carfagna, E., 2013. Review of crop yield forecasting methods and early warning systems. Report presented to First Meeting of the Scientific Advisory Committee of the Global Strategy to Improve Agriculture and Rural Statistics FAO, Headquarters, Rome, Italy, pp. 1-56.

Champion, I., and Guyot, G., 1991. Generalized formulation for semi-empirical radar models representing crop backscattering. ESA Physical Measurements and Signatures in Remote Sensing, 1, pp. 803-806.
Chauhan, S., Srivastava, H. S., and Patel, P., 2017. Improved parameterization of water cloud model for hybrid-polarized backscatter simulation using interaction factor, The International Archives of the Photogrammetry, Remote Sensing and Spatial Information Sciences, 42 (61). DOI: 10.5194/isprsarchives-XLII-4-W2-61-2017

Cloude, S. R., Goodenough, D. G., and Chen, H., 2012. Compact decomposition theorey. IEEE Geoscience and Remote Sensing Letters, 9(1), pp. 28-32.

Dabrowska-Zielinska, K., Inoue, Y., Kowalik, W., and Gruszczynska, M., 2007. Inferring the effect of plant and soil variables on C- and L- band SAR backscatter over agricultural fields, based on model analysis. Advances in Space Research, 39(1), pp. 139-148.

Doraiswamy, P. C., Moulin, S., Cook, P. W., and Stern, A., 2003. Crop yield assessment from remote sensing. Photogrammetric Engineering \& Remote Sensing, 69 (6), pp. 665-674.

El Hajj, M., Baghdadi, N., Zribi, M., Belaud, G., Cheviron, B., Courault, D., and Charron, F., 2016. Soil moisture retrieval over irrigated grassland using X-band SAR data. Remote Sensing of Environment, 176, pp. 202-218.

Fontanelli, G., Paloscia, S., Zribi, M., and Chahi, A., 2013. Sensitivity analysis of X-band SAR to wheat and barley leaf area index in the Merguellil basin. Remote Sensing Letters, 4 (11), pp. 1107-1116.

Fransoon, J. E. S., 1999. Estimation of stem volume in boreal forests using ERS-1 C- and JERS-1 L-band SAR data International Journal of Remote Sensing, 20 (1), pp. 123-137.

Kumar, S., 2009. Retrieval of forest parameters from Envisat ASAR data for biomass inventory in Dudhwa National Park, UP, India. M.Sc. Thesis, Faculty of Geo-information Science and Earth Observation, University of Twente.

Macelloni, G., Paloscia, S., Pampaloni, P., Marliani, F., and Gai, M., 2001. The Relationship between the backscattering coefficient and the biomass of narrow and broad leaf crops. IEEE Transactions on Geoscience and Remote Sensing, 39 (4), pp. 873-884.

Mishra, M. D., Patel, P., Srivastava, H. S., Shukla, A., Patel, P. R., and Shukla, A. K., 2015. Approach for absolute radiometric calibration of RISAT-1 SAR data using standard target. International Journal of Remote Sensing \& Geoscience, 4 (1), pp. 28-32.

Paloscia, S., 1998. An empirical approach to estimating leaf area index from multifrequency SAR data. International Journal of Remote Sensing, 19 (2), pp. 359-364.

Paloscia, S., Pettinato, S., Santi, E., Notarnicola, C., Pasolli, L. and Reppucci, A., 2013. Soil moisture mapping using Sentinel-1 images: Algorithm and preliminary validation. Remote Sensing Environment, 134, pp. 234-248. 
Patel, P., and Srivastava, H. S., 2013. Ground truth planning for Synthetic Aperture Radar (SAR): Addressing various challenges using statistical approach. International Journal of Advancement in Remote Sensing, GIS and Geography, 1 (2), pp. 01-17.

Patel, P., Srivastava, H. S., and Navalgund, R. R., 2006. Estimating wheat yield: An approach for estimating number of grains using cross-polarized Envisat-1 ASAR data. Microwave Remote Sensing of the Atmosphere and Environment. In Proc. of SPIE, 6410, pp. 1-12.

Patel, P., Srivastava, H. S., Panigrahy, S., and Parihar, J. S., 2006. Comparative evaluation of the sensitivity of multipolarized multi-frequency SAR backscatter to plant density. International Journal of Remote Sensing, 27 (2), pp. 293-305.

Peregon, A., and Yamagata, Y., 2013. The use of ALOS/PALSAR backscatter to estimate above-ground forest biomass: A case study in Western Siberia. Remote Sensing of Environment, 137, pp. 139-146.

Poolla, S. B., 2013. Polarimetric scattering model for biophysical characterization of multilayer vegetation using space borne PolSAR data. M.Sc. Thesis, Faculty of Geoinformation Science and Earth Observation, University of Twente.

Prevot, L., Champion, I., and Guyot, G., 1993. Estimating surface soil moisture and leaf area index of a wheat canopy using dual-frequency ( $\mathrm{C}$ and $\mathrm{X}$ bands) scatterometer. Remote Sensing of Environment, 46, pp. 331-339.

Prevot, L., Champion, I., and Guyot, G., 1993. Estimating surface soil moisture and leaf area index of a wheat canopy using dual-frequency ( $\mathrm{C}$ and $\mathrm{X}$ bands) scatterometer. Remote Sensing of Environment, 46, pp. 331-339.

Raney, R. K., 2007. Hybrid-polarity SAR architecture. IEEE Transactions on Geoscience and Remote Sensing, 45 (11), pp. 3397-3404.

Raney, R. K., Cahill, J. T. S., Patterson, G. W., and Bussey, D. B. J., 2012. The m-chi decomposition of hybrid polarimetric dual-polarimetric radar data with application to lunar craters. Journal of Geophysical Research, 117 (E00H21), pp. 1-8. doi:10.1029/2011JE003986.

Sharma, P. K., Kumar, D., and Srivastava, H. S., 2016. Soil moisture retrieval under wheat crop using RISAT-1 hybrid polarimetric SAR data. National Symposium on Recent Advances in Remote Sensing and GIS with Special Emphasis on Mountain Ecosystems, 7-9 Dec 2016, Dehradun, India.

Sikdar, M., and Cumming, I., 2004. A modified empirical model for soil moisture estimation in vegetated areas using SAR data. In Proceedings of the 2004 IEEE International Geoscience and Remote Sensing Symposium, Anchorage, AK, USA, 20-24 September 2004, 2, pp. 803-806.

Sivasankar, T., Kumar, D., Srivastava, H. S., and Patel, P.,
2018. Advances in radar remote sensing of agricultural crops: a review. International Journal on Advanced Science, Engineering and Information Technology, 8(4), pp. 1126-1137.

Srivastava, H. S., 2007. Interaction of multi-frequency multipolarized DLR ESAR data with various targets: a case study with $\mathrm{C}, \mathrm{L}$ and $\mathrm{P}$ bands acquired at all the four linear $(\mathrm{VV}, \mathrm{HH}$, $\mathrm{VH}$ and HV) polarizations. JEP-MW Conference, 15-16 May 2007, SAC, Ahmedabad, pp. 2:12-23.

Srivastava, H. S., Patel, P., and Navalgund, R. R., 2006. How far SAR has fulfilled its expectation for soil moisture retrieval. Microwave Remote Sensing of the Atmosphere and Environment V, Proc. of SPIE, 6410 (641001), pp. 1-12.

Srivastava, H. S., Patel, P., Sharma, Y., and Navalgund, R. R., 2009. Large-area soil moisture estimation using multiincidence-angle RADARSAT-1 SAR data. IEEE Transactions on Geoscience and Remote Sensing, 47 (8), pp. 2528-2535.

Stokes, G.G., 1852. On the composition and resolution of streams of polarized light from different sources. Transactions of the Cambridge Philosophical Society, 9, pp. 399-416.

Ulaby, F.T., Allen, C.T., Eger, G. and Kanemasu, E., 1984. Relating the microwave backscattering coefficient to leaf area index. Remote Sensing of Environment, 14 (1-3), pp.113-133.

Yamaguchi, Y., Yajima, Y., and Yamada, H., 2006. A fourcomponent decomposition of POLSAR images based on the coherency matrix. IEEE Geoscience and Remote Sensing Letters, 3 (3), pp. 292-296. 